\title{
Morphology and Optical Investigations of InAs-QD/GaAs Heterostructures Obtained by Ion-Beam Sputtering
}

\author{
S. N. Chebotarev, ${ }^{1,2}$ A. S. Pashchenko, ${ }^{2}$ V. A. Irkha, ${ }^{3}$ and M. L. Lunina ${ }^{2}$ \\ ${ }^{1}$ Platov South-Russian State Polytechnic University (NPI), Prosvescheniya Street 132, Novocherkassk 346428, Russia \\ ${ }^{2}$ Southern Scientific Center, Russian Academy of Sciences, Chekhova Street 41, Rostov-on-Don 344006, Russia \\ ${ }^{3}$ Inversiya Special Design and Engineering Bureau, Zorge Street 7, Rostov-on-Don 344104, Russia
}

Correspondence should be addressed to S. N. Chebotarev; chebotarev.sergei@gmail.com

Received 1 October 2015; Revised 7 January 2016; Accepted 20 January 2016

Academic Editor: Yoke K. Yap

Copyright (c) 2016 S. N. Chebotarev et al. This is an open access article distributed under the Creative Commons Attribution License, which permits unrestricted use, distribution, and reproduction in any medium, provided the original work is properly cited.

\begin{abstract}
A new ion-beam sputtering technique for obtaining self-assembled InAs quantum dots on GaAs (001) substrates is proposed. The current paper demonstrates that a temperature increase in a range from 450 to $550^{\circ} \mathrm{C}$ at ion current of $120 \mu \mathrm{A}$ and energy of $150 \mathrm{eV}$ leads to an expansion of average sizes of InAs hut-quantum dots. According to atomic force and electron microscopy, photoluminescence, and capacity-voltage measurements it was found that an increase of ion-beam current from 60 to $120 \mu \mathrm{A}$ at a temperature of $500^{\circ} \mathrm{C}$ and energy of $150 \mathrm{eV}$ slightly enlarges the average sizes of quantum dots from $15 \mathrm{~nm}$ to $18 \mathrm{~nm}$ while their dispersion is about $30 \%$. At a current of $180 \mu \mathrm{A}$ a surface density is $1.3 \cdot 10^{11} \mathrm{~cm}^{-2}$, but under these conditions there is a very high dispersion of quantum dots up to $50 \%$.
\end{abstract}

\section{Introduction}

Quantum dot heterostructures based on semiconductor compounds are the best candidates to produce modern and effective tunneling switches [1], lasers [2], and optoelectronic [3] and photovoltaic devices [4]. Molecular beam epitaxy [5] and chemical vapor deposition [6] are well studied and represent the most used techniques to grow self-assembled quantum dot heterostructures. Besides these ones, other classical methods are being actively employed to produce nanostructured materials with quantum dots. Among them are liquid phase epitaxy [7], pulsed-laser deposition [8], electron beam sputtering [9], and ion-beam sputtering [10].

Ion-beam sputtering of germanium films was firstly carried out by Krikorian and Sneed [11]. Their work demonstrated a significant potential of the method and became a starting point of its development. Ion-beam homoepitaxy of silicon on substrates with crystallographic orientation (001) was partially investigated by Lee et al. [12]. High-vacuum ion-beam heteroepitaxy of germanium nanometer films on silicon substrate was carried out by Aleksandrov's group [13].
They were the first observing a self-assembled growth of germanium quantum dot nanostructures.

Furthermore, ion-beam sputtering was used for heteroepitaxy of Ge on GaAs substrates [14] and $\mathrm{GaAs}_{1-x} \mathrm{P}_{x}$ on $\mathrm{Si}$ substrates [15]. In our recent works, we also used this method to show a possibility of producing Ge [16] and InAs [17] quantum dots. In addition, the effect of ion-beam bombarding of semiconductor surfaces is used at least for two applications. First, it is employed to form nanostructured patterns on semiconductor surfaces [18]. And second, this effect was applied to stimulate nucleation nanoislands by ionassisted molecular beam epitaxy [19]. It allowed the reduction of QDs' size and their dispersion.

The aim of this paper is to study morphological and optical properties of InAs quantum dots grown on GaAs (001) substrates by ion-beam sputtering using low-energy argon ions.

\section{Experimental Methods}

2.1. Facilities. Samples were grown by an ion-beam sputtering equipment. The growth mechanism of quantum dots is 
the Stranski-Krastanov mode and it is the same as in the other methods [20]. Quantum dots formed due to the release of the stress from the lattice mismatch. The sputtering equipment consists of a vacuum chamber, a prevacuum pump Varian DS 302, a turbomolecular pump with magnetic bearing Leybold Turbovac 340, a gridded ion-beam source KDC 40, and a cryopanel, cooled with liquid nitrogen. For vacuum measurements we used an Ionivac ITR 90 active sensor based on the Bayard-Alpert principle. Pressure in the chamber after 6 hours of pumping was at $5 \cdot 10^{-7} \mathrm{~Pa}$. An advantage of the selected ion-beam source is a relatively independent control of energy and ion current. Magnitude of the generated current depends on ion energy $E_{\mathrm{Ar}+}$ and voltage at the first grid electrode $U_{\text {grid }}$.

The energy range was chosen in a view of achieving extremely low growth rates for gallium arsenide and indium arsenide. Changing voltage on the first grid of ion-beam source one is able to vary beam current $I_{\text {beam }}$ from 30 to $200 \mu \mathrm{A}$ within the energy range of $100-300 \mathrm{eV}$. Hence, using the ion-beam sputtering method it is possible to attain a growth rate from 0.07 to $0.5 \mathrm{ML} / \mathrm{s}$ for the selected materials.

Ion-beam profile measurement was carried out by a Faraday cup with a $1 \mathrm{~mm}$ inlet. The beam is considerably blurred at a low voltage. Increasing voltage focuses beam, but it expands at bias more than $300 \mathrm{~V}$. It should be noted that the beam profile keeps a Gaussian form under all the experimental conditions.

Substrate temperature was varied by a $750 \mathrm{~W}$ highvacuum resistive heater with a temperature rate from 0.1 to $10 \mathrm{~K} / \mathrm{s}$. Temperature was measured by an $S$-type thermocouple $(\mathrm{Pt}-10 \% \mathrm{Rh}-\mathrm{Pt})$. This type of thermocouple has a wide range of temperature measurements from -50 to $1768^{\circ} \mathrm{C}$. Temperature measuring above $600^{\circ} \mathrm{C}$ was duplicated by an optical pyrometer.

2.2. Targets and Substrates Preparation. Targets and substrates were 2-inch single-crystal gallium arsenide and indium arsenide wafers with a (100) surface orientation. GaAs and InAs targets first are etched by argon ions at energy of $180 \mathrm{eV}$ with etching rate of $0.3 \mathrm{ML} / \mathrm{s}$. It was shown in [21] that at energies up to $200 \mathrm{eV}$ the effect of argon incorporation into semiconductors wafers is not observed. Oxide film containing other adsorbed impurities under these conditions was effectively removed. Mixing and segregation of the binary compounds were not observed.

The described method of target cleaning is not suitable to prepare single-crystal substrates because of radiation damage. Defects formed during ion etching are not critical for the creation of a mass flow by ion sputtering but are not acceptable for producing self-assembled quantum dot heterostructures. High temperature heating without chemical pretreatment is not effective. It should take place to create on a surface of wafers a protective nanofilm. Subsequent short annealing eliminates both oxide film and carbon impurities. There is a significant quantity of implementation of the cleaning method. The used cleaning technique was a combination of Pramatarova et al's [22] and Cho's [23] methods. Impurities and protective oxide layer were eliminated by annealing of wafers in the growth chamber at a temperature of $560-580^{\circ} \mathrm{C}$.
2.3. Analytical Equipment. Surface morphology was investigated on an atomic force microscope Solver HV in a tapping mode. This method was used to estimate a surface density of quantum dots and to prepare size distribution diagrams. For these investigations we used silicon NSG10 AFM probes from NT-MDT with a curvature radius of $10 \mathrm{~nm}$ and did them under the following conditions: pressure in the microscope vacuum chamber of $10^{-3} \mathrm{~Pa}$, temperature of $293 \mathrm{~K}$, and the scan rate of $0.5 \mathrm{~Hz}$. Studies were conducted using positional labels, which improved reproducibility of the results [24]. Quantum dots were also examined on a transmitted electron microscope Tecnai G2 Spirit with a system of preliminary preparation of samples. Photoluminescence of nanostructures was studied in the spectral range from 620 to $2480 \mathrm{meV}$ at a temperature of $77 \mathrm{~K}$. An injection laser with a wavelength of $402 \mathrm{~nm}$ and a radiation power of $8.5 \mathrm{~mW}$ was used as a source of optical radiation. Photoluminescence signals were detected on a MDR 23 monochromator and germanium p-i$\mathrm{n}$ photodiode cooled with liquid nitrogen. $\mathrm{CV}$ characteristics were obtained with a Spectrolab at Stepanov Institute of Physics.

\section{Results and Discussions}

3.1. Loss Factor and Uniformity. We propose using a loss factor $R_{\text {loss }}$ and a uniformity coefficient $R_{\text {unf }}$ to evaluate quality of the ion-beam sputtering process. The loss factor shows a proportion of sputtered atoms which are not deposited on the substrate. The factor characterizes integral mass transfer efficiency and mainly depends on a geometry of the ion-beam-target-substrate system. We found $R_{\text {loss }}$ by weighing the substrate before and after the sputtering procedure using precision analytical balance XSE 105DU. The error in determining the change in mass of nanolayer does not exceed $1.5 \%$. Loss factor is given by

$$
R_{\mathrm{loss}}=1-\frac{e N_{A}\left(m_{\mathrm{sub}}^{*}-m_{\mathrm{sub}}^{0}\right)}{M Y I t}
$$

where $e$ is the elementary charge, $N_{A}$ is the Avogadro constant, $M$ is molar mass, $Y$ is the sputtering yield, $I$ is the ion current, $t$ is process time, and $m_{\text {sub }}^{0}$ and $m_{\text {sub }}^{*}$ are masses of the substrate before and after sputtering. The total error in determining the loss factor is about $5 \%$.

Second coefficient $R_{\text {unf }}$ is used to evaluate a spatial uniformity of the growth substance flow. It depends on energy and ion-beam profile.

The uniformity coefficient is given by

$$
R_{\mathrm{unf}}=\frac{h_{\mathrm{max}}-h_{\min }}{h_{\max }}
$$

where $h_{\max }$ and $h_{\min }$ are the maximum and the minimum thickness of a layer deposited on a substrate. We measured the thickness of the layer on the atomic force microscope Solver HV. The error was less than $3 \%$.

Experimental loss factors $R_{\text {loss }}$ for GaAs and InAs as functions of a target-substrate distance are presented in Figure 1. 


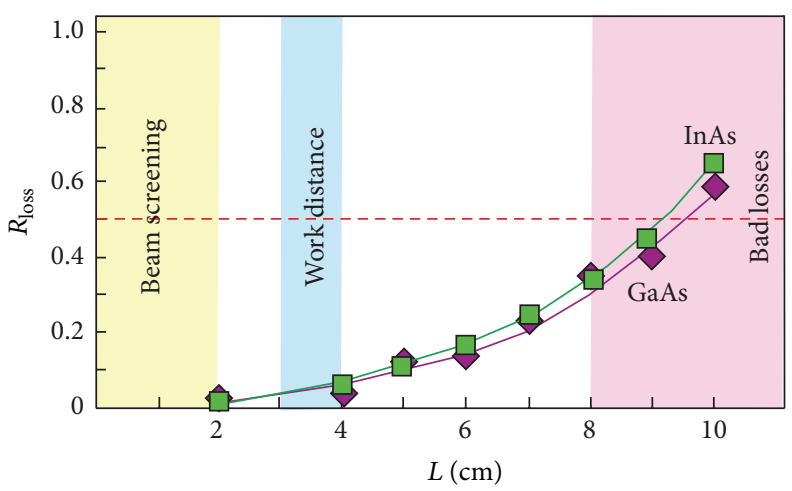

FIGURE 1: Distance dependence of the InAs and GaAs loss factors.
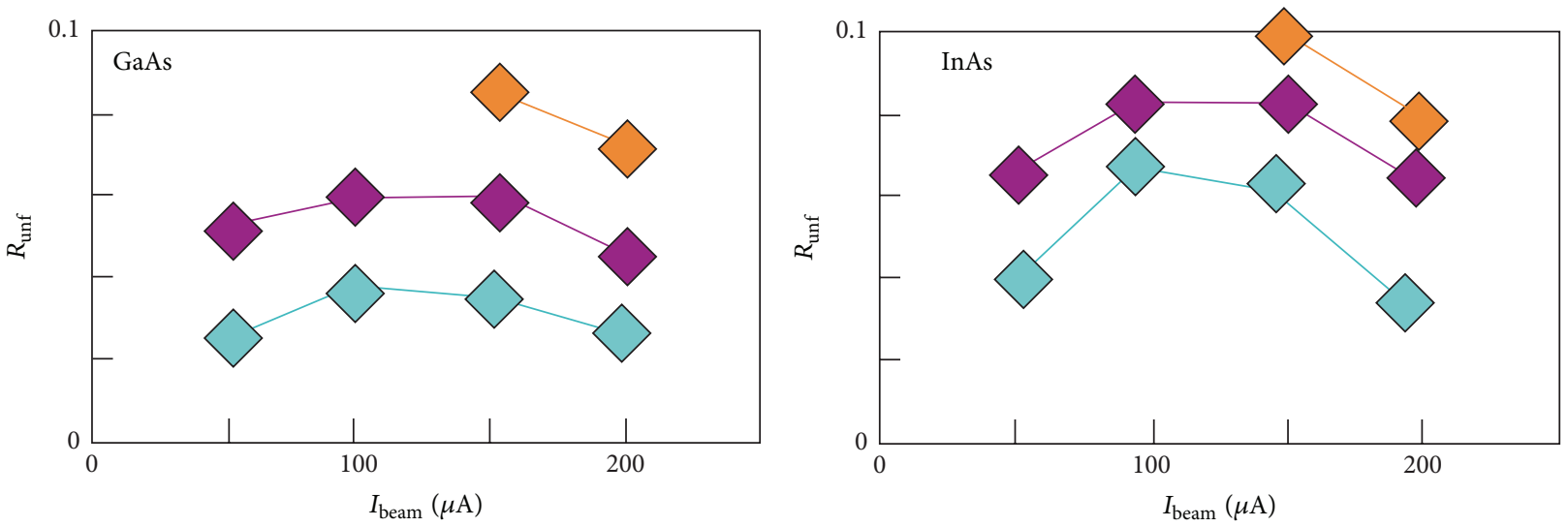

$$
\begin{aligned}
& E_{\mathrm{Ar}+}(\mathrm{eV}) \\
& \diamond 150 \\
& \diamond 300 \\
& \diamond 500
\end{aligned}
$$

FIgURE 2: Uniformity-current characteristic for GaAs and InAs.

It is shown that there is a smooth increase in loss factors of the materials due to removal of substrate. Based on this data one can say that the optimum target-substrate distance is in the range from 3 to $4 \mathrm{~cm}$. In addition to the target-substrate distance, an incidence angle $\alpha$ between the ion beam and the target plays an important role.

Loss factors for gallium arsenide and indium arsenide strongly depend on the angle. This is especially true for indium arsenide with the narrowest differential sputtering yield [25]. For all the target-substrate distances there are significant losses at the small incidence angles because of a preferential sputtering in the sector outside substrate. For angles in the range from 40 to 60 degrees the loss coefficients for the semiconductors are less than $10 \%$.

It is obvious that the beam profile affects the uniformity of deposited layers. The obtained results for the different ion currents and ion energies for a $50^{\circ}$ incidence angle and for a $4 \mathrm{~cm}$ target-substrate distance are presented in Figure 2.

It is technically impossible to achieve low beam currents at energy of $500 \mathrm{eV}$. Hence, for these energies the experimental data presents only two values of currents: $150 \mu \mathrm{A}$ and $200 \mu \mathrm{A}$. For gallium arsenide the uniformity is good enough.
This is due to the wide diagram of differential sputtering yield for GaAs, smoothing heterogeneity of current density profile. In contrast, the uniformity of indium arsenide is worse because of the narrow diagram of differential sputtering yield. But it is worth pointing out that the uniformity does not exceed $10 \%$ at ion energy of $0.5 \mathrm{keV}$. Furthermore we showed that the low-energy sputtering at $150 \mathrm{eV}$ allows a uniformity not worse than $4 \%$ for GaAs and $7 \%$ for indium arsenide. Our studies point to a possibility of controlling rate and uniformity within a wide range of energies and beam currents.

3.2. Size and Surface Density of InAs Quantum Dots. We investigated morphology evolution of InAs nanolayer grown on GaAs substrates by ion-beam sputtering at ion-beam current of $120 \mu \mathrm{A}$ and substrate temperature of $500^{\circ} \mathrm{C}$. Incidence angle was $50^{\circ}$ and ion energy was $150 \mathrm{eV}$. Deposition rate was set to $0.09 \mathrm{ML} / \mathrm{s}$.

From Figure 3 we can see that the deposition during 30 seconds allowed forming of a wetting layer of InAs, containing nucleation centers of nanoislands. The three-minute growth led to formation of InAs island array. Precipitation 

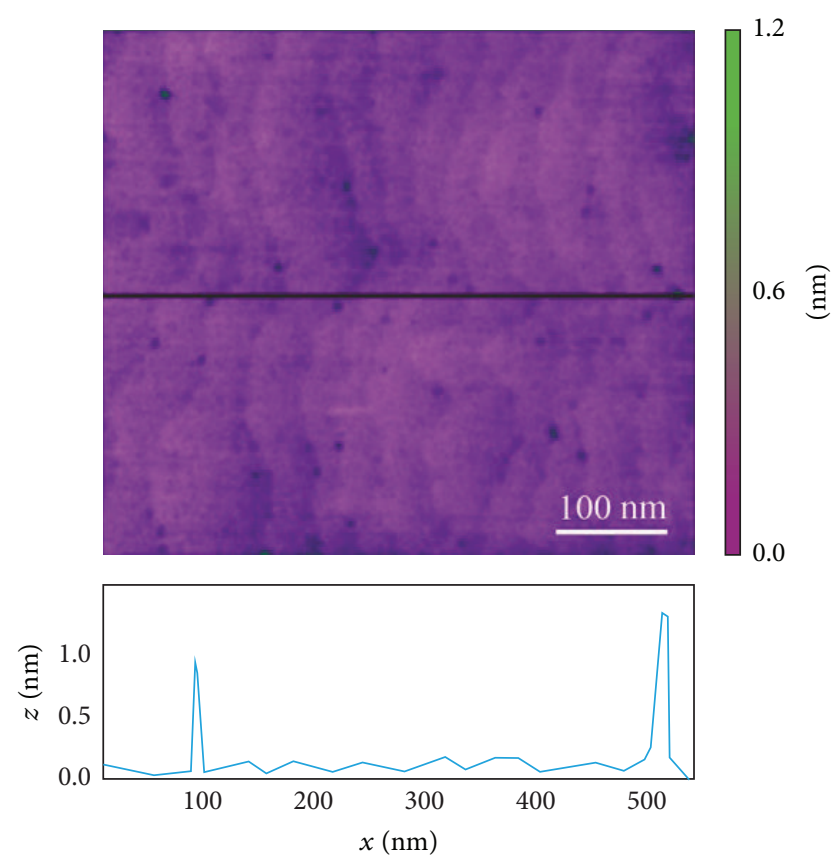

(a) $t=30 \mathrm{~s}$
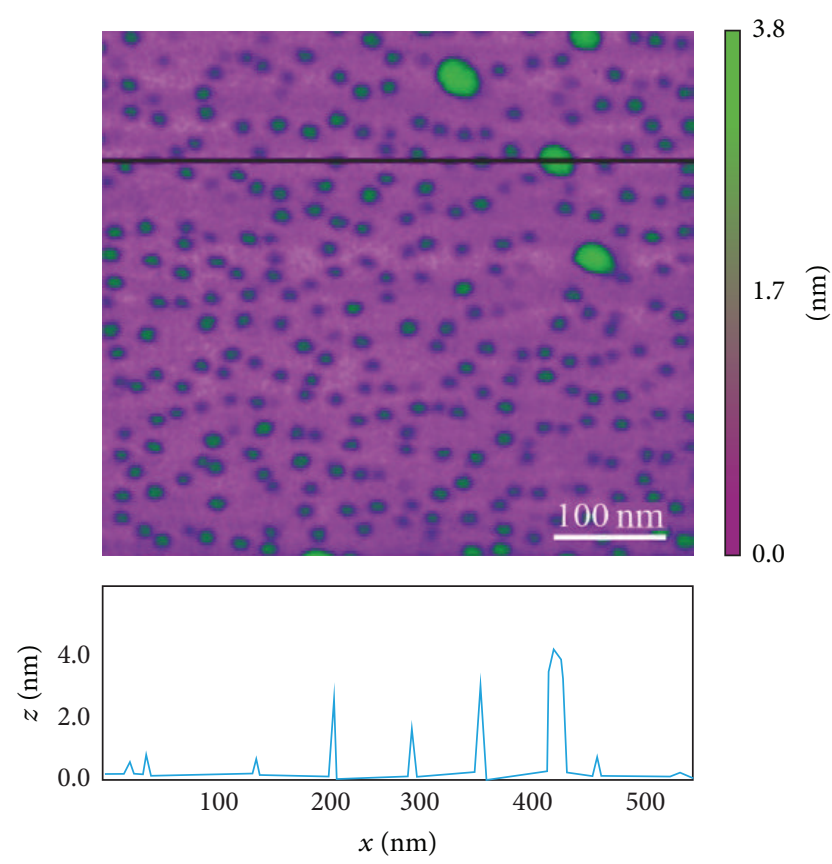

(b) $t=180 \mathrm{~s}$
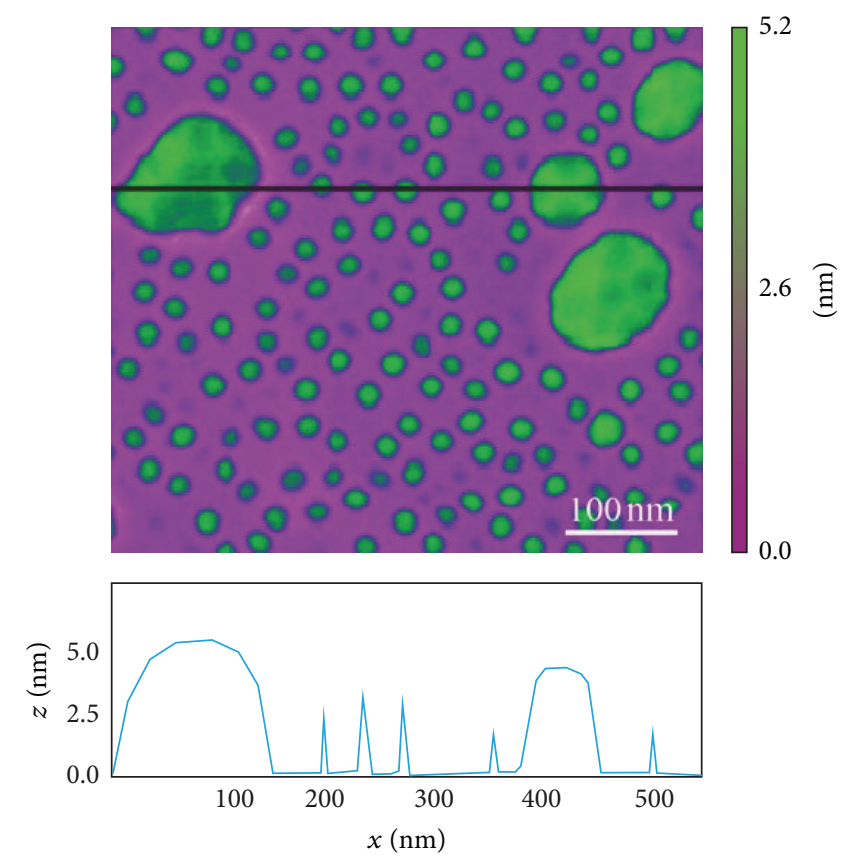

(c) $t=300 \mathrm{~s}$

Figure 3: Morphology of InAs/GaAs at different stages of growth.

within five minutes caused transformation of hut-clusters into dome-type objects.

It is important to note an existence of a time range when dimensions of nanoislands vary slightly. The existence of this range provides a technological stability to ion-beam sputtering. The described transformational transition is illustrated in Figure 4.

Quantitative parameter of the array is an average lateral size of nanoislands $D_{\mathrm{av}}$. Average size $D_{\mathrm{av}}$ is determined for each substrate temperature (from 400 to $650^{\circ} \mathrm{C}$ ) at constant energy of $150 \mathrm{eV}$ and ion-beam current of $120 \mathrm{~mA}$ by atomic force microscopy and these results are shown in Figure 5.

As one can see in Figure 6 a gain in temperature leads to the expansion of nanoislands' sizes. But it is not a linear dependence. At temperatures above $500^{\circ} \mathrm{C}$ average size increases fast and then at about $600^{\circ} \mathrm{C}$ the process saturates. There is an optimum temperature within the range from 450 to $550^{\circ} \mathrm{C}$. Under these conditions a dispersion of sizes is less 


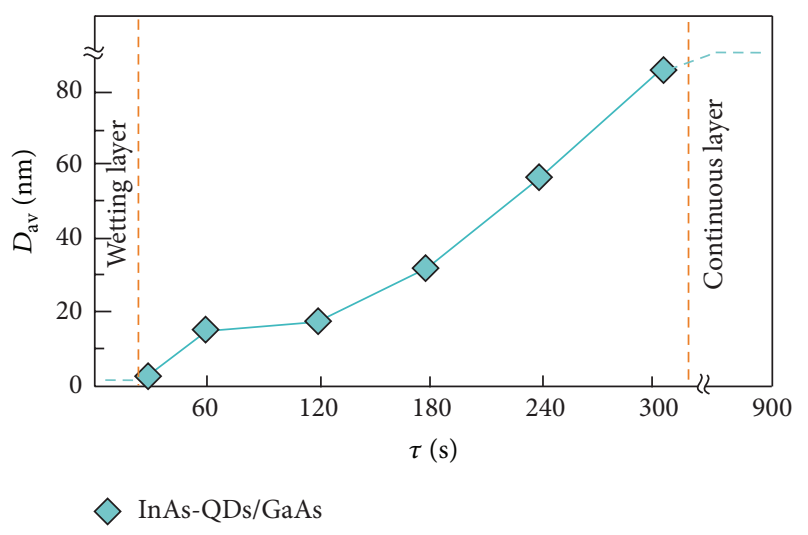

FIGURE 4: Time chart of the nanoisland transformation during ionbeam sputtering.

than $28 \%$. Therefore the range may be used to produce InAs hut-dots on GaAs substrates by ion-beam sputtering.

Another important factor is a surface density depicted in Figure 7. At temperatures from 400 to $500^{\circ} \mathrm{C}$ the surface density of InAs nanodots is about $10^{11} \mathrm{~cm}^{-2}$. Then at a temperature above this high bound the surface density goes down from $1.1 \cdot 10^{11} \mathrm{~cm}^{-2}$ to $0.4 \cdot 10^{11} \mathrm{~cm}^{-2}$.

Investigation of influence of ion current on ion-beam sputtering nanoislands was carried out under the following conditions. Substrate's temperature was $500^{\circ} \mathrm{C}$ and ion energy was set to $150 \mathrm{eV}$. Ion current was varied from 60 to $180 \mu \mathrm{A}$. Deposition time was chosen based on obtaining quasi-layers of equal thicknesses. Increasing in ion-beam current does not significantly affect an average size of InAs nanoislands, as one can observe it in Figure 8. However, at high currents $(I=$ $180 \mu \mathrm{A}$ ) the hut-clusters reach average size of $21 \mathrm{~nm}$ (hutclusters), but at $60 \mu \mathrm{A}$ they have sizes less than $10 \mathrm{~nm}$. Sizes of the dome-structures expanded from $77 \mathrm{~nm}$ at ion current of $60 \mu \mathrm{A}$ to $84 \mathrm{~nm}$ at $180 \mu \mathrm{A}$.

Increasing in ion-beam current primarily results in formation of more dense arrays. Summary of this study is represented in Figure 9.

Energy of argon ions bombarding target determines rate and spatial distribution of layer thickness. Deposition of nanometer layers requires the usage of minimum possible rate. It makes inappropriate deposition for energies more than $300 \mathrm{eV}$. Figure 10 demonstrates the results of investigation of energy influence on size and surface density of InAs nanoislands grown by ion-beam sputtering.

The smallest sizes are observed at energies in the range from 150 to $200 \mathrm{eV}$, when nanostructures with dimensions less than $20 \mathrm{~nm}$ were formed. Further increase of energy led to enlargement of average sizes of nanoislands. It is interesting to note that at energy of $120 \mathrm{eV}$ the islands size is $23 \mathrm{~nm}$ and it is more than the size of nanoislands produced at $150 \mathrm{eV}$. Apparently, this is due to a significant energy dispersion of ions generated by ion source.

The surface density of nanoislands slightly increases with boosting ion energy, as shown in Figure 11. This comes from the fact that the surface density depends primarily on the ion current density and not energy.
The surface density of InAs nanodots was about 10 . $10^{10} \mathrm{~cm}^{-2}$. Note that the chosen and used in the preceding paragraphs ion energies of $150 \mathrm{eV}$ are based on the established patterns.

3.3. $C V$ Spectroscopy. Effect of the size quantization was investigated by capacitance-voltage method. Samples were produced by ion-beam sputtering at ion energy of $150 \mathrm{eV}$. Cross section of a sample is illustrated in Figure 12. Four kinds of samples were grown. The first sample has no nanoislands inside. The second, the third, and the fourth samples have an array of nanoislands between GaAs layers. Nanoislands were obtained at three different currents: $60 \mu \mathrm{A}, 120 \mu \mathrm{A}$, and $180 \mu \mathrm{A}$ accordingly. The left side of the figure shows a layer cross section; the right side is a temperature map.

Deposition was done at energy of $150 \mathrm{eV}$. There is a TEM image with nanoislands layer on the frame in Figure 12. The CV-measured data is shown in Figure 13.

There are saturation ranges on curves for the samples with quantum dot layers. Saturation range is a region in which the curve is parallel to abscise. This is due to the fact that energy levels in quantum dots are fully filled with charge carriers and the capacity of the layer with quantum dots is constant. For the samples obtained at higher beam current one can see that the saturation ranges were expanded. This effect can be explained by the fact that the surface density is increased (see Figure 9).

3.4. Photoluminescence. For photoluminescence measurements we obtained three samples at ion current of $120 \mu \mathrm{A}$ and at different energies of $150 \mathrm{eV}, 200 \mathrm{eV}$, and $300 \mathrm{eV}$. Investigation of photoluminescence of these nanostructures was conducted in the spectral range from 650 to $1200 \mathrm{meV}$ at $77 \mathrm{~K}$. Figure 14 illustrates photoluminescence data.

There are two features of the PL spectra of the samples under study. The first feature is the left peak of quantum dots broadens at higher ion energies. In our opinion, the broadening of PL spectra can be explained by high dispersion of quantum dots, produced at high ion energies. The second one leads to a blue shift of the peak because of increase in size of quantum dots. These results correlate well with the morphology data.

\section{Conclusions}

In this study, we have investigated the effect of InAs quantum dots growing on GaAs (001) substrates via ion-beam sputtering. It was found that a gain in temperature at ion current of $120 \mu \mathrm{A}$ and energy of $150 \mathrm{eV}$ leads to expansion of average sizes of InAs hut-quantum dots. In the temperature range from 450 to $500^{\circ} \mathrm{C}$ the average size is less than $15 \mathrm{~nm}$ and surface density is about $1.2 \cdot 10^{11} \mathrm{~cm}^{-2}$. At temperature higher than $500^{\circ} \mathrm{C}$, density sharply reduces to $0.4 \cdot 10^{11} \mathrm{~cm}^{-2}$. Note that at higher temperatures there is a quantity of dome-structures which is not suitable to produce size-effect semiconductor devises. Gain in ion-beam current from 60 to $120 \mu \mathrm{A}$ at temperature of $500^{\circ} \mathrm{C}$ and energy of $150 \mathrm{eV}$ slightly increases average sizes from $15 \mathrm{~nm}$ to $18 \mathrm{~nm}$; dispersion of 


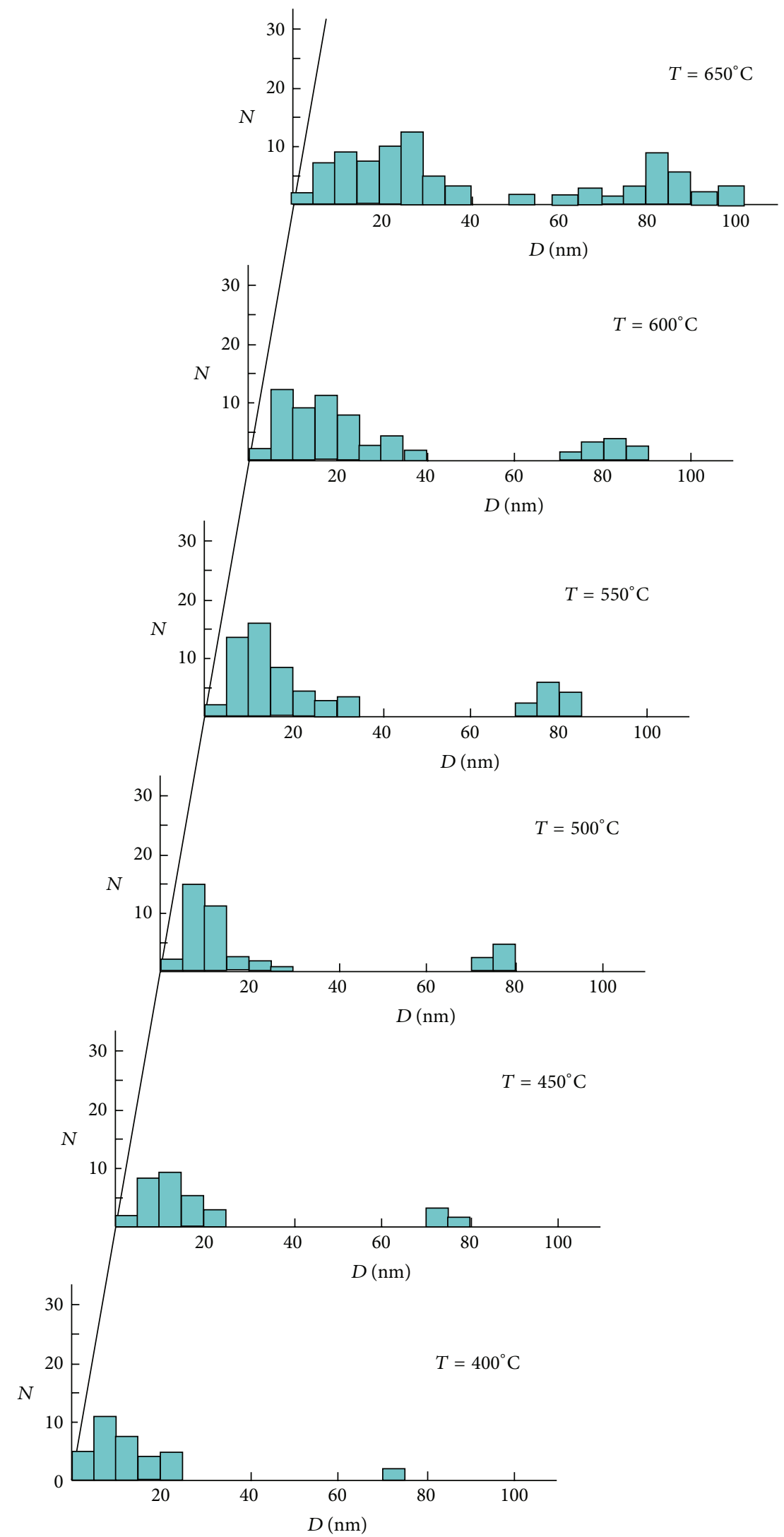

FIGURE 5: Size distributions of InAs nanoislands at different substrate temperatures, where $N$ is a number of islands. 


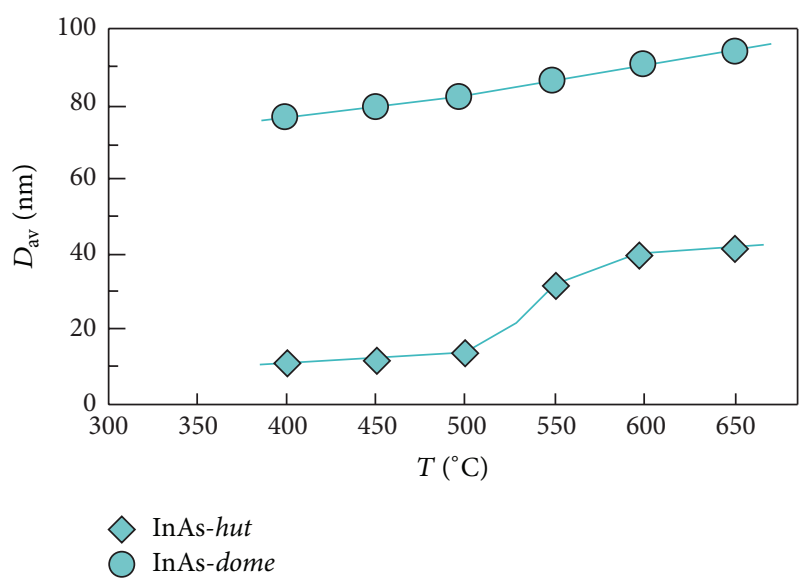

Figure 6: Temperature dependence of InAs nanoislands average size.

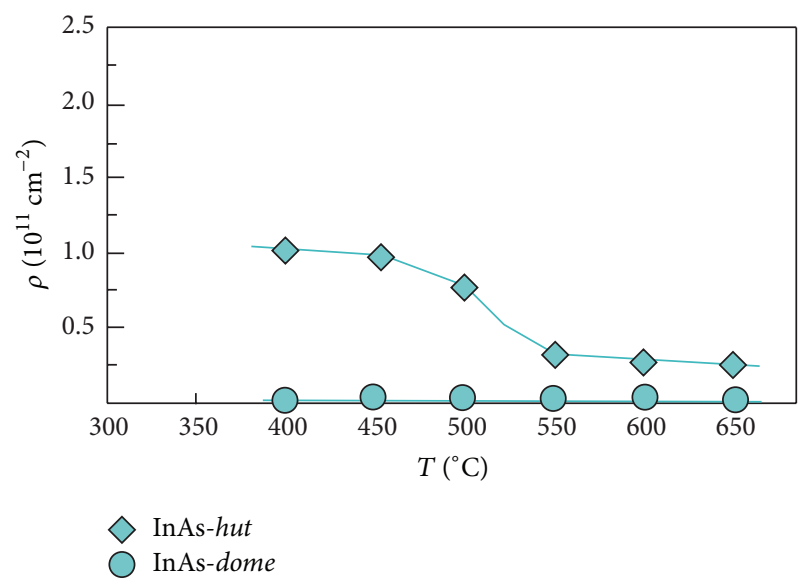

Figure 7: Temperature dependence of InAs nanoislands surface density.

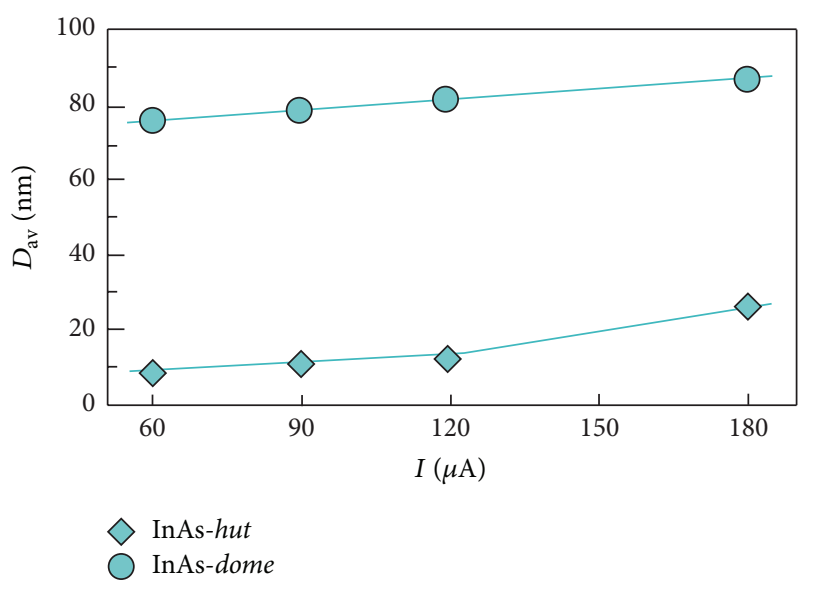

FIgURE 8: Average size of InAs nanoislands as a function of ionbeam current.

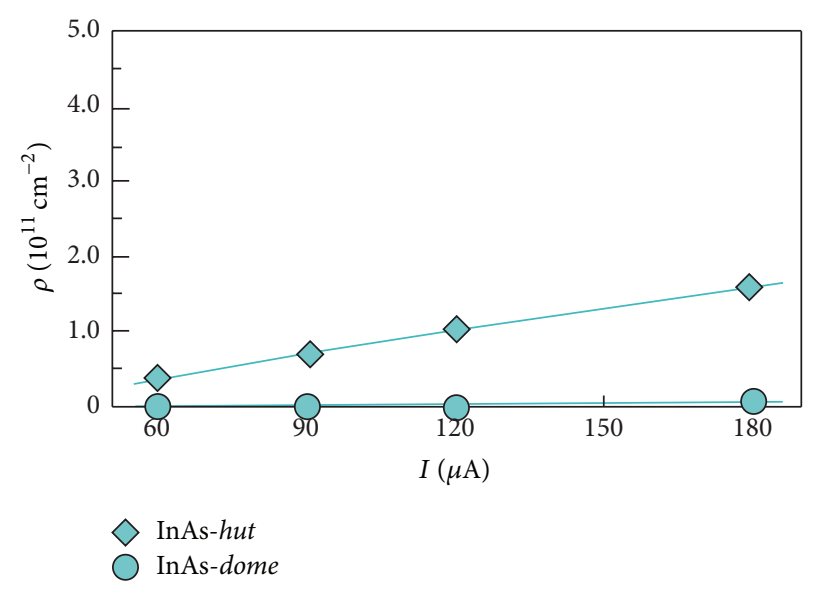

FIgURE 9: Surface density of InAs nanoislands as a function of ionbeam current.

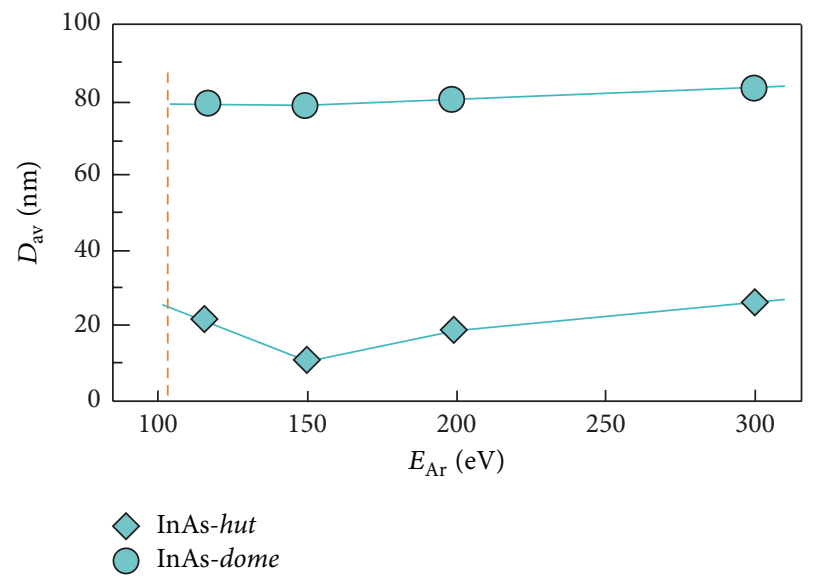

FIgUre 10: Average size of InAs nanoislands as a function of ion energy.

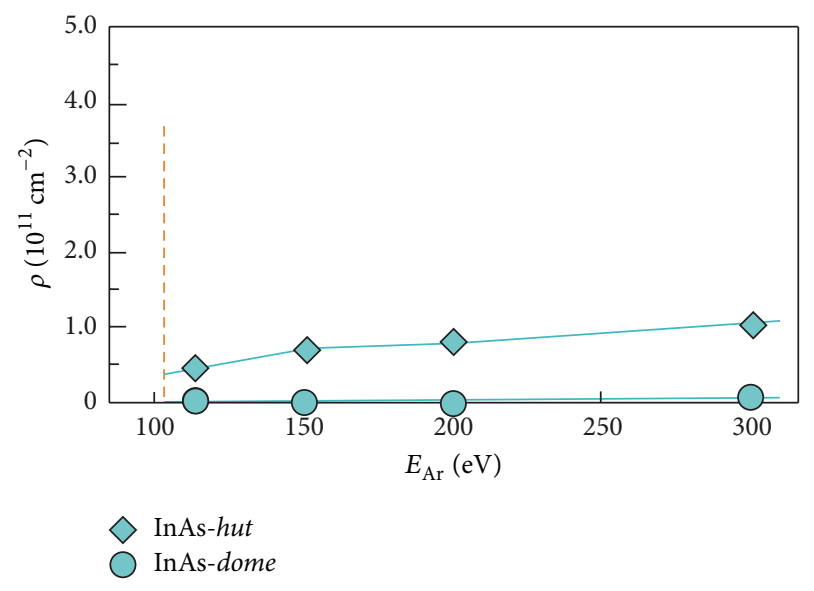

FIGURE 11: Surface density of InAs nanoislands as a function of ion energy. 


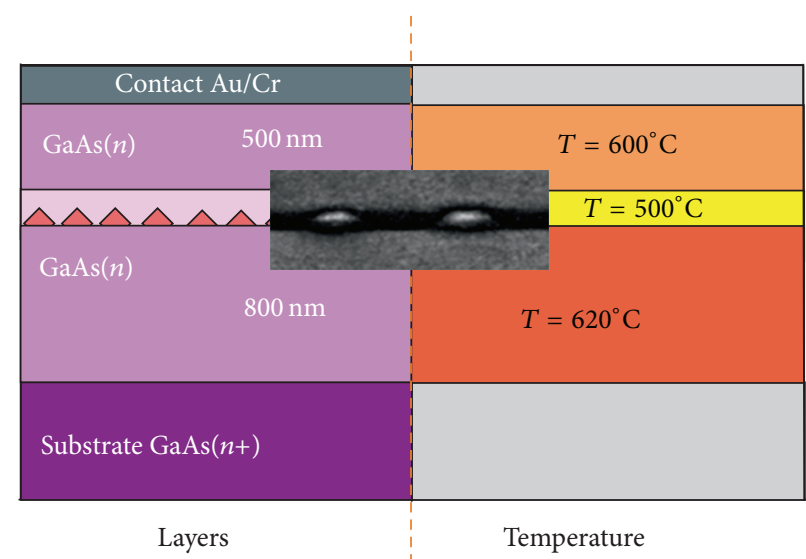

FIGURE 12: Cross section and temperature map of a sample for CV investigation.

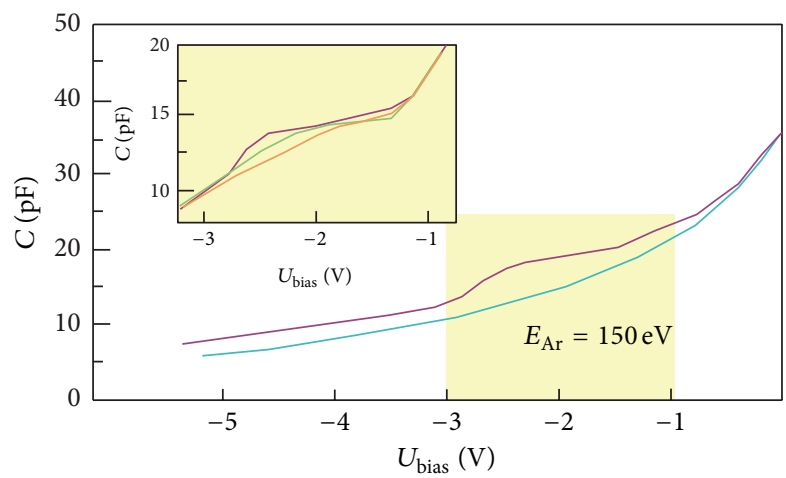
- Without QDs
QDs $60 \mu \mathrm{A}$
QDs $120 \mu \mathrm{A}$

FIGURE 13: Capacitance-voltage characteristics.

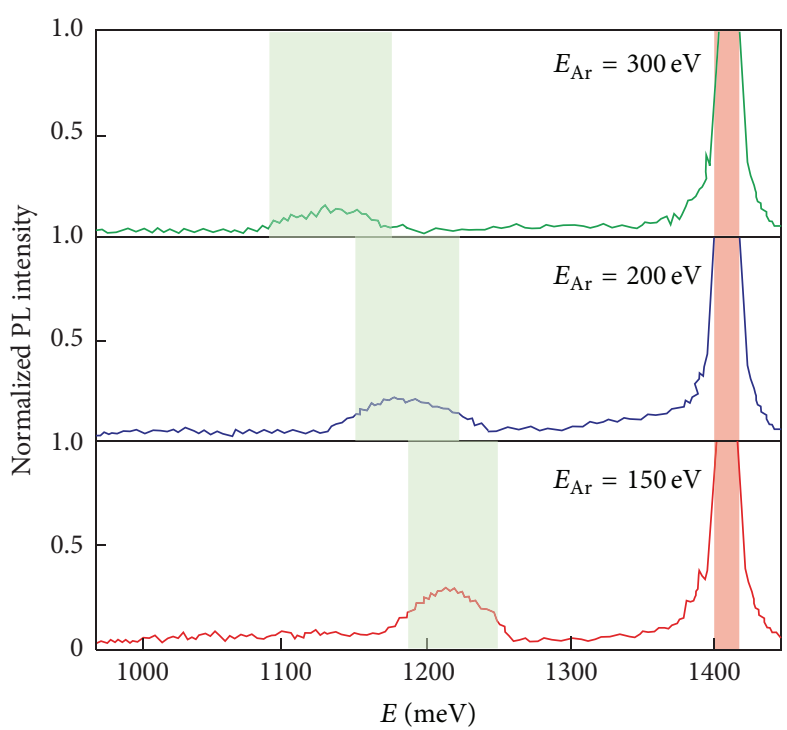

FIgURE 14: Photoluminescence spectra. quantum dots is about $30 \%$. At current of $180 \mu \mathrm{A}$ the surface density is $1.3 \cdot 10^{11} \mathrm{~cm}^{-2}$, but under these conditions there is very high dispersion of quantum dots up to $50 \%$. At energies higher than $300 \mathrm{eV}$ the average size of quantum dots is more than $35 \mathrm{~nm}$ and they have a dispersion of $45 \%$. Further work will study multilayered quantum dot structures to provide a better understanding of ion-beam sputtering process.

\section{Conflict of Interests}

The authors declare that there is no conflict of interests regarding the publication of this paper.

\section{Acknowledgments}

This work was financially supported by the Russian Ministry of Education and Science within the Federal Targeted Program "Research and Development of High-Priority Areas of the Scientific-Technological Complex of Russia (2014-2020)", Grant no. 14.576.21.0033, Project ID RFMEFI57614X0033. The reported study was also partially funded by the Russian Foundation for Basic Research according to the research Project 15-08-08263_a.

\section{References}

[1] C. H. Lee, S. S. Qin, M. A. Savaikar et al., "Room-temperature tunneling behavior of boron nitride nanotubes functionalized with gold quantum dots," Advanced Materials, vol. 25, no. 33, pp. 4544-4548, 2013.

[2] P. Spencer, E. Clarke, R. Murray, K. M. Groom, R. R. Alexander, and R. A. Hogg, "Subthreshold diode characteristics of InAs/GaAs quantum dot lasers," Physical Review B-Condensed Matter and Materials Physics, vol. 83, no. 20, Article ID 205407, 5 pages, 2011.

[3] W. W. Wang, F. M. Guo, and Y. Q. Li, "Modeling and simulation of a resonant-cavity-enhanced InGaAs/GaAs quantum dot photodetector," Advances in Condensed Matter Physics, vol. 2015, Article ID 847510, 6 pages, 2015. 
[4] A. Luque, A. Martí, and C. Stanley, "Understanding intermediate-band solar cells," Nature Photonics, vol. 6, no. 3, pp. 146152, 2012.

[5] V. V. Mamutin, V. M. Ustinov, J. Boetthcher, and H. Kuenzel, "MBE growth of $5 \mu \mathrm{m}$ quantum cascade lasers," Technical Physics Letters, vol. 36, no. 5, pp. 408-411, 2010.

[6] S. Li, Q. Chen, S. Sun et al., "InAs/GaAs quantum dots with wide-range tunable densities by simply varying V/III ratio using metal-organic chemical vapor deposition," Nanoscale Research Letters, vol. 8, article 367, 2013.

[7] K. D. Moiseev, Y. A. Parkhomenko, A. V. Ankudinov et al., "InSb/InAs quantum dots grown by liquid phase epitaxy," Technical Physics Letters, vol. 33, no. 4, pp. 295-298, 2007.

[8] B. Eisenhawer, D. Zhang, R. Clavel, A. Berger, J. Michler, and S. Christiansen, "Growth of doped silicon nanowires by pulsed laser deposition and their analysis by electron beam induced current imaging," Nanotechnology, vol. 22, no. 7, Article ID 075706, 7 pages, 2011.

[9] V. C. Elarde, R. Rangarajan, J. J. Borchardt, and J. J. Coleman, "Room-temperature operation of patterned quantum-dot lasers fabricated by electron beam lithography and selective area metal-organic chemical vapor deposition," IEEE Photonics Technology Letters, vol. 17, no. 5, pp. 935-937, 2005.

[10] S. N. Chebotarev, A. S. Pashchenko, A. Williamson, L. S. Lunin, V. A. Irkha, and V. A. Gamidov, "Ion beam crystallization of InAs/GaAs(001) nanostructures," Technical Physics Letters, vol. 41, no. 7, pp. 661-664, 2015.

[11] E. Krikorian and R. J. Sneed, "Epitaxial deposition of germanium by both sputtering and evaporation," Journal of Applied Physics, vol. 37, no. 10, pp. 3665-3673, 1966.

[12] N.-E. Lee, G. Xue, and J. E. Greene, "Epitaxial Si(001) grown at $80-750^{\circ} \mathrm{C}$ by ion-beam sputter deposition: crystal growth, doping, and electronic properties," Journal of Applied Physics, vol. 80, no. 2, pp. 769-780, 1996.

[13] L. N. Aleksandrov, R. N. Lovyagin, O. P. Pchelyakov, and S. I. Stenin, "Heteroepitaxy of germanium thin films on silicon by ion sputtering," Journal of Crystal Growth, vol. 24-25, pp. 298301, 1974.

[14] X.-S. Wang, J. Brake, R. J. Pechman, and J. H. Weaver, "Effect of ion sputtering on Ge epitaxy on GaAs(110)," Applied Physics Letters, vol. 68, no. 12, pp. 1660-1662, 1996.

[15] Y. Takaishi and T. Itoh, "Properties of $\mathrm{GaAs}_{1-x} \mathrm{P}_{x}$ epitaxial films prepared by ion beam sputter deposition," Electronics and Communications in Japan Part II: Electronics, vol. 75, no. 12, pp. 97-106, 1992.

[16] L. S. Lunin, S. N. Chebotarev, and A. S. Pashchenko, "Structure of $\mathrm{Ge}$ nanoclusters grown on $\mathrm{Si}(001)$ by ion beam crystallization," Inorganic Materials, vol. 49, no. 5, pp. 435-438, 2013.

[17] L. S. Lunin, S. N. Chebotarev, A. S. Pashchenko, and S. A. Dudnikov, "Correlation between the size and photoluminescence spectrum of quantum dots in InAs-QD/GaAs," Journal of Surface Investigation. X-Ray, Synchrotron and Neutron Techniques, vol. 7, no. 1, pp. 36-40, 2013.

[18] S. Facsko, T. Dekorsy, C. Trappe, and H. Kurz, "Self-organized quantum dot formation by ion sputtering," Microelectronic Engineering, vol. 53, no. 1-4, pp. 245-248, 2000.

[19] A. V. Dvurechenskii, J. V. Smagina, R. Groetzschel et al., "Ge/Si quantum dot nanostructures grown with low-energy ion beamassisted epitaxy," Surface and Coatings Technology, vol. 196, no. 1-3, pp. 25-29, 2005.
[20] S. N. Chebotarev, A. S. Paschenko, L. S. Lunin, and V. A. Irkha, "Features in the formation of Ge/Si multilayer nanostructures under ion-beam-assisted crystallization," Technical Physics Letters, vol. 39, no. 8, pp. 726-729, 2013.

[21] P. Rabinzohn, G. Gautherin, B. Agius, and C. Cohen, "Cleaning of $\mathrm{Si}$ and GaAs crystal surfaces by ion bombardment in the eV range: influence of bombarding energy and sample temperature on damage and incorporation," Journal of the Electrochemical Society, vol. 131, no. 4, pp. 905-914, 1984.

[22] L. D. Pramatarova, E. B. Savova, G. M. Minchev, and M. G. Mihailov, "Preparation of GaAs substrates for MBE," Crystal Research and Technology, vol. 23, no. 1, pp. K11-K15, 1988.

[23] A. Y. Cho and I. Hayashi, "Surface structures and photoluminescence of molecular beam epitaxial films of GaAs," Solid-State Electronics, vol. 14, no. 2, pp. 125-132, 1971.

[24] V. N. Lozovskii, S. N. Chebotarev, V. A. Irkha, and G. V. Valov, "Formation and use of position marks in scanning probe microscope," Technical Physics Letters, vol. 35, no. 8, pp. 737-738, 2010.

[25] P. Sigmund, "Recollections of fifty years with sputtering," Thin Solid Films, vol. 520, no. 19, pp. 6031-6049, 2012. 

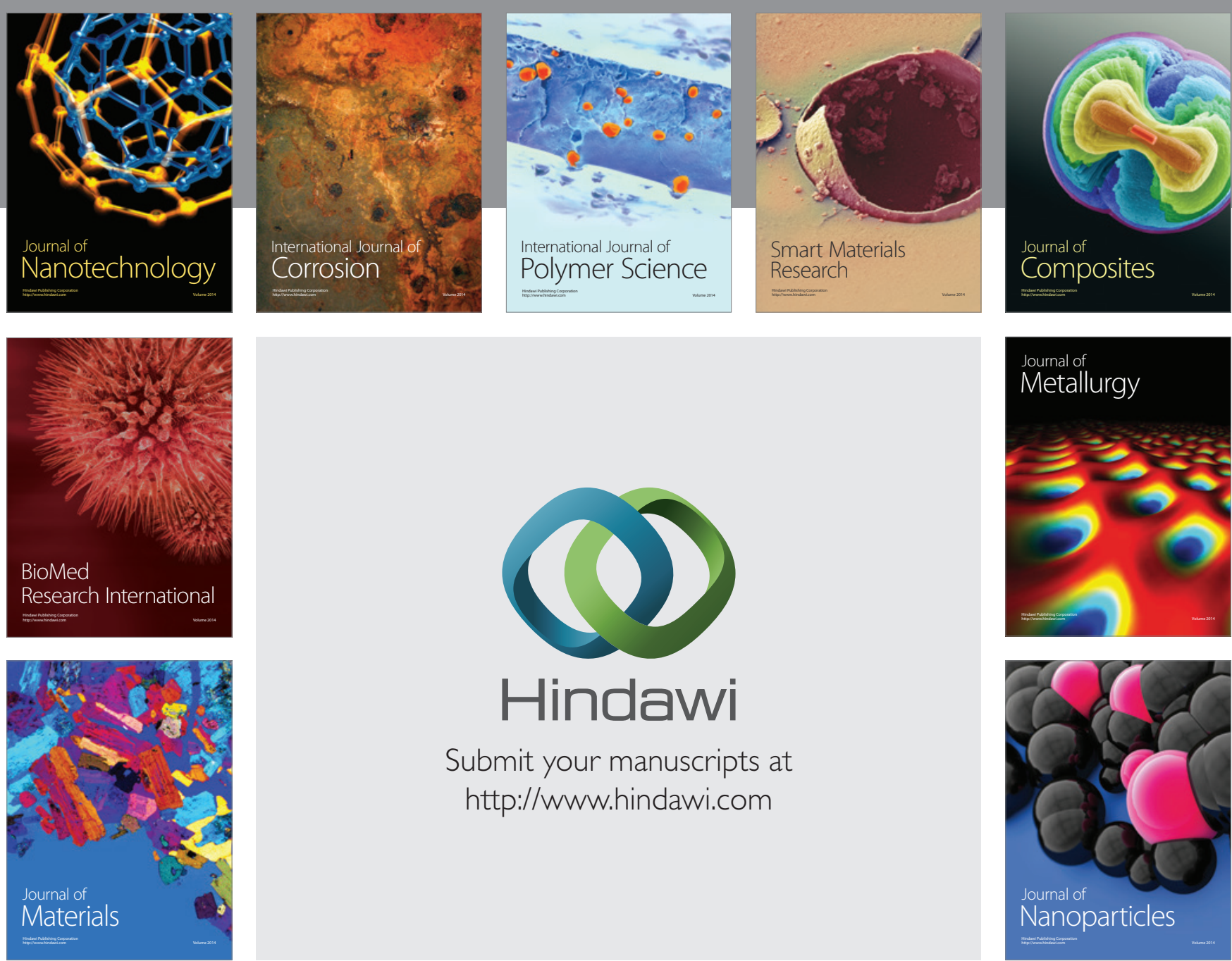

\section{Hindawi}

Submit your manuscripts at

http://www.hindawi.com

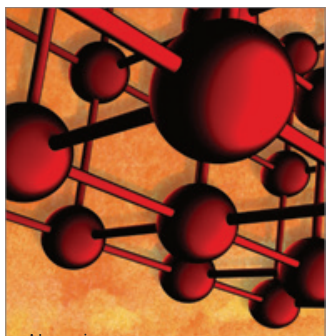

Materials Science and Engineering
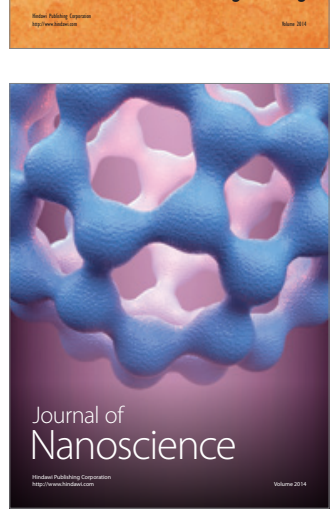
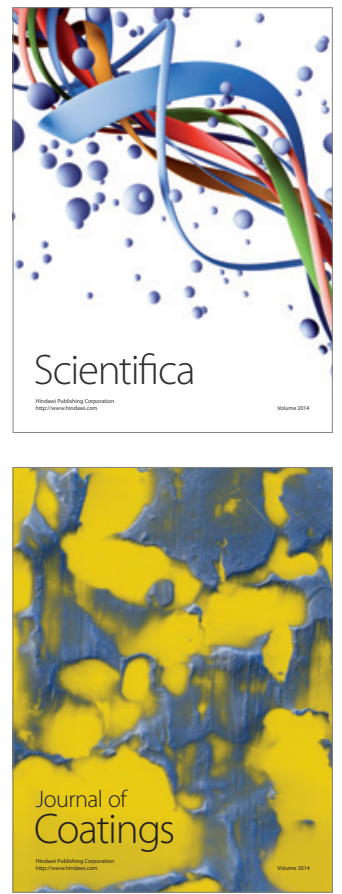
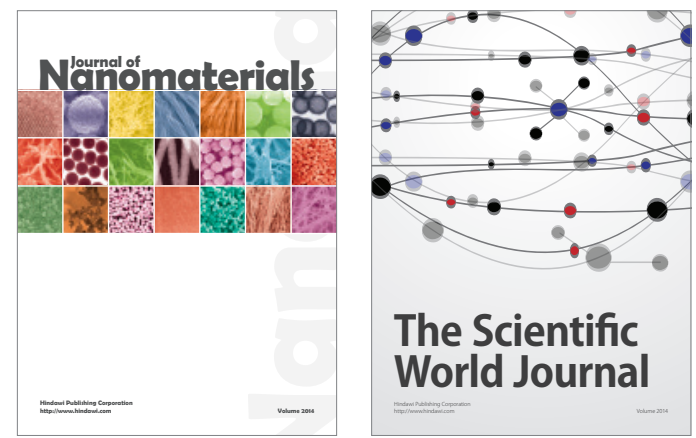

The Scientific World Journal
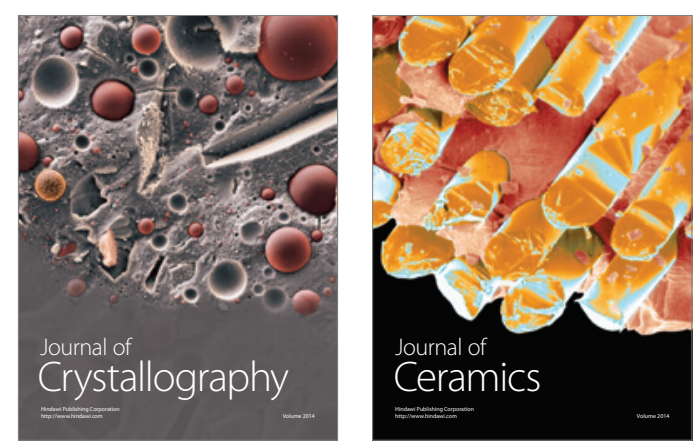
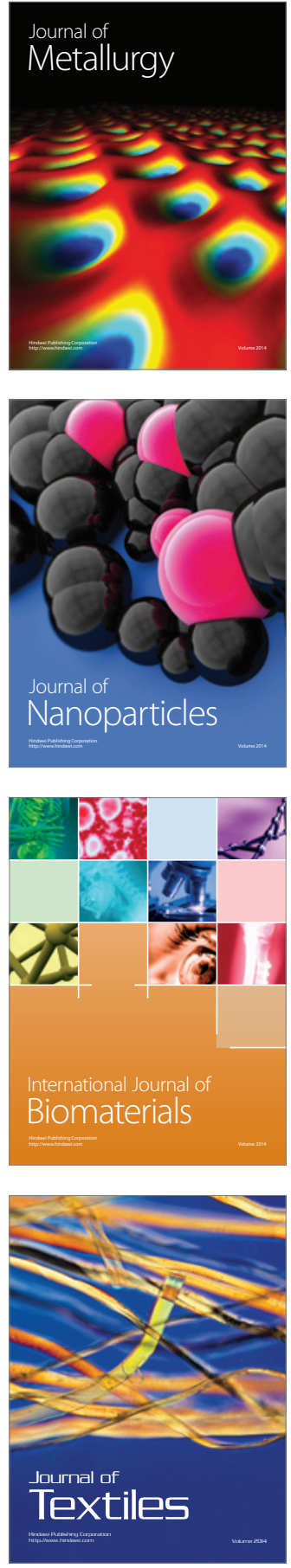